\title{
Personnel Improvement Plan: a professionalism assignment for engineering students
}

\section{Dr. Mohammad Habibi, Minnesota State University, Mankato \\ Mr. Ronald R Ulseth, Iron Range Engineering}

Ron Ulseth, P.E. is Co-Director of IRE as well as an instructor of technical competencies in thermodynamics, fluid mechanics, and heat transfer. Ulseth has been teaching engineering fundamentals courses since 1988. He was a lead developer in the Itasca Community College Engineering program. Ulseth led a team of 10 engineering educators from around the United States to develop the Iron Range Engineering program. In addition to being a engineering faculty member, he is a licensed professional mechanical engineer and recently retired after 25 years in the United States Navy Reserve as an Engineering Duty Officer. Ulseth has a Bachelors of Civil Engineering from the University of North Dakota and a Masters of Mechanical Engineering from the University of Central Florida. He is a member of ASEE (American Society of Engineering Education), NSPE (National Society of Professional Engineers), and is a life time member of Tau Beta Pi.

Mr. Andrew Lillesve, IRE 


\title{
Personal Improvement Plan: a professionalism assignment for engineering students
}

\begin{abstract}
:
Iron Range Engineering (IRE) is an innovative project-based engineering program which places high value on the integration of technical learning and professional skills. The IRE students must enroll and complete one Professionalism course per semester (Professionalism I through Professionalism IV) during their four semester upper-division experience. As part of each professionalism course, students complete and submit an assignment named Personal Improvement Plan (PIP). Each semester, through various experiences within the project teams and discipline-specific workshops, each student self-assesses his/her improvement in the following categories: Leadership, Learning About Learning, Teamwork, Technical Writing, Technical Presentation, Professional Responsibility and Ethical Decision Making. By completing this assignment, students are expected to recognize their areas of improvement and plan to achieve their professional goals while completing the program. In this paper, we discuss the PIP assignment, student learning outcomes, students' perceptions and future improvement that can be made on the assignment.
\end{abstract}

\section{Introduction}

Personal Improvement Plan (PIP), also called Personal Development Plan (PDP) or Individual Development Plan (IPD), is a written plan that frameworks a student's professional goals and steps needed to meet those goals. The Personal Improvement Plan generally consists of three basic components: (1) recognizing professional goals and objectives, (2) evaluating an individual's skill set to achieve the objectives, and (3) drafting a plan to acquire the skills and competencies needed to meet the professional goals ${ }^{1}$. These components will make students more effective, independent and confident self-directed learners. There are three types of skills required to establish and continue a successful professional career. These skills include: technical skills and professional skills (known as academic skills), personal and social, and employability skills (such as work experience, internship, and co-op). In a PIP process, students identify their positions in all these skills, and develop an action plan to achieve their short and long- term goals.

The PIP process has been around for last three decades but its recognition as a best practice in professional development is fairly new. In some counties such as United Kingdom, PIP has been well recognized and has become a policy in the higher education section ${ }^{2}$. The effectiveness of PIP processes has also been studied ${ }^{3,4}$. Bulock et al. ${ }^{3}$ concluded that the one-to-one dialogue between students and tutors significantly affects the success of PIP. Beausaert et al. ${ }^{4}$ examined the effects of using a personal development plan (PDP) on the undertaking of learning activities and the employee's job competencies. By collecting data from 2,271 pharmacy assistants, their findings indicate that employees who use PIP process involve with more learning activities than non-users. However, they stressed that the PIP tool is effective if used continuously. 
A number of recommendations have been made to improve the effectiveness of PIPs ${ }^{3}$. For instance, it has been suggested that schools should provide guidance for students to conduct PIPs by assigning appropriate $\operatorname{staff}^{5}$. Additionally, periodic reviews should be made to ensure learning outcome and career progress of students' PIPs ${ }^{6}$. Furthermore, It has recommended that PIP could also be developed through reflective thinking if a reflective habit among the students is created by instructors ${ }^{5}$. Although the purpose of PIP is to recognize, reflect and plan actions, the existing literature indicates that practices of PIP vary widely ${ }^{2}$. In addition to improvement, several means are suggested to implement PIP processes for students ${ }^{7}$. These methods include adapting PIPs into curriculum with structured format, making it mandatory but students choose the format, or making it optional for students.

Iron Range Engineering program (IRE) is a project-based, non-traditional engineering program that promotes learning of technical concepts and professionalism in the context of industrysponsored projects ${ }^{8,9}$. IRE has identified the importance of PIP and has adopted PIP practice as a part of the curriculum. The PIP tool at IRE is structured around and supported by the ABET student outcomes(insert reference to ABET a-k). Each semester, IRE students complete and deliver their PIPs as a part of their professionalism course. PIP not only has helped the students recognize their professional strengths and weaknesses, it also helped students to track their path to become engineering professionals.

In this paper, we describe the IRE program, the curriculum and how PIP is integrated in the curriculum, the students' perspectives on PIP, and we will also discuss future improvement that can be made and the important learning outcomes for engineering students. At the end, we explain how other entities could learn from this continuing professional development experience.

\section{Iron Range Engineering}

In the center of Minnesota's Mesabi Iron Range, an innovative, new model for engineering education was established in spring 2010, named Iron Range Engineering (IRE). This program is a result of collaboration between Itasca Community College (ICC) and Minnesota State University-Mankato (MSU) and is administered by both institutions. The IRE model is a $100 \%$ project-based pedagogy and promotes self-directed learning, professionalism skills, and engineering design. In this project-based program, students work on design projects defined by industries in the area. Working in close contact with industry, the IRE students are able to develop their professional skills as well as acquire technical competencies in the context of their design projects. The IRE program values skills such as technical acumen, reflection, strong teamwork, communication \& leadership, a strong moral compass, ethics, diversity, and cultural awareness $^{10,11}$.

IRE's innovative model was designed with several goals in mind. The first was to further develop engineering education. Second, IRE looks to grow the local economy by creating new local business and providing current companies with highly skilled technical employees who have significant integrated technical and professional knowledge and skills. This model has been implemented by offering a four-year engineering degree to high performing, local community college graduates, allowing them to remain in northern Minnesota. The impact of the recruiting and retention projects will give incentive to prospective students to stay in northern Minnesota as they continue their engineering education and further iterate IRE's model. 
In both the industry-based projects and in individual learning, students must make decisions about how to best learn or complete their tasks. Their learning is, in other words, self-directed. Given the self-directed nature of the IRE curriculum, the faculty recognized the need to support student's metacognitive and self-reflective skills. To structure this support, for every one of the aforementioned competencies, students must complete a "metacog". Metacog is the term students use for both the metacognition process and the summary document that is delivered at the end of each technical competency. The process includes organizing their learning as it happens, reflecting on the learning on a frequent basis, making qualitative judgments on the learning, and then making regulative changes based on the judgments. The summary is documentation of the process. These processes and the memo externalize specific aspects of metacognition including awareness of actions and reflection on what one knows and doesn't. Beyond the general challenges of self-regulating their learning, students find it particularly challenging to manage their time.

The IRE students choose their own emphasis for the degree, by enrolling in specific competencies or projects. This not only increases students' interests and motivation but also provides an environment for deeper learning and longer retention of the material. At IRE, there are no classes in the form of lecture halls; the students learn the content relevant to their project. Each technical competency accounts for one credit towards graduation and students can accumulate multiple credits in a content area. The learning material of a competency may differ from one student to another. The students choose what and when they want to learn and what technical evidence they offer in support of their learning.

IRE curriculum consists of 60-credits, 32 technical and 28 professional and design credits. The technical credits consist of 6 mechanical core credits, 6 electrical core credits, 4 general engineering core credits and 16 elective credits (each referred to as a competency), in which all students gain proficiency. The elective competencies, also referred to as advanced competencies, are developed by students and instructors according to the student's interest or his/her project goals. However, the core competencies, both mechanical and electrical, are well-structured and matched with the subjects commonly taught at traditional institutions. Completing these core competencies are the major requirements for IRE students to graduate.

IRE students earn a Bachelors of Science in Engineering (BSE) if they successfully complete all 60-credits. Furthermore, students are able to earn an emphasis in specific engineering areas if they take and successfully pass 12 of 16-credits of elective competencies in specific areas such as mechanical, electrical, biomedical, etc.

A typical student takes 15-credit per semester. These 15-credits include 8 technical credits and 7 professional and design credits. In the IRE curriculum, there are no formal courses in the sense that each course would have a different schedule of weekly meetings and that faculty members are assigned to teach separate courses. 


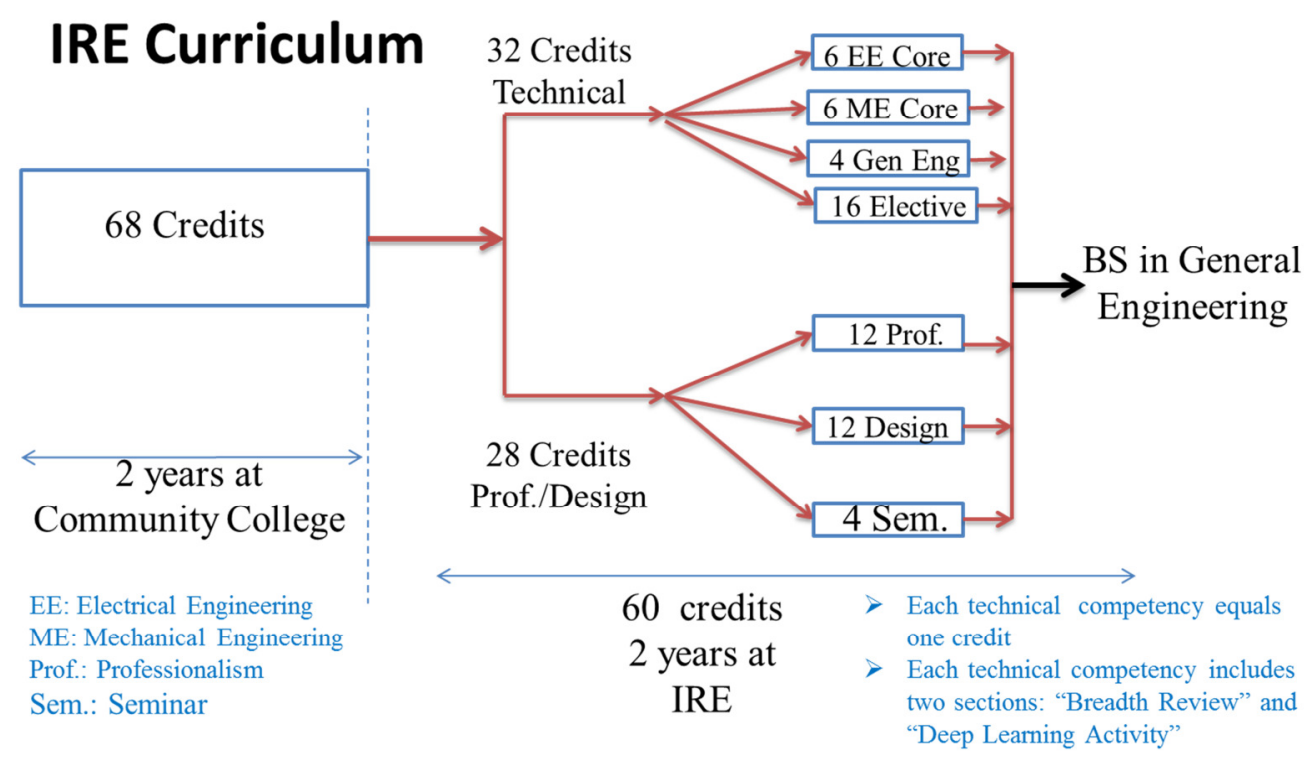

Figure 1. IRE Curriculum

IRE has realized the importance of professionalism and has implemented it as a specified part of the curriculum. IRE students have to enroll in and complete 12 credits of professionalism to complete their Bachelor of Science in Engineering degree. These 12 credits are divided into four courses called Professionalism I, II, III and IV taken each semester they are at IRE. Each of these courses includes various components such as life-long learning, leadership, effective communication, teamwork, engineering ethics, and community outreach ${ }^{8}$.

\section{Personal Improvement Plan (PIP)}

Each semester, through various experiences within the project teams and discipline-specific workshops, IRE students self-assess their improvement in seven categories. These categories include leadership, learning about learning, teamwork, writing skills, presenting skills, professional responsibility, and ethical decision making. These categories are selected based on ABET student outcomes and recommendation for the program academic advising board. Table1 exhibits these categories and connection with ABET student outcomes. Students reflect on each category in a chapter of their PIPs, chapter 1 through chapter 7. In addition to these seven chapters, students are required to write an introduction section. The written introduction acts as an executive summary of the entire student's learning and continuous improvement in the course of the semester. The target audience is a future employer who will need the context and purpose of student work described in order to understand the individual chapters within the collection. At IRE, learning happens in the domains of design project, technical learning, and professional learning. Students must address their learning in these areas, but avoid too much detail that might be covered in later individual chapters. They also are required to include information that situates the learning described within the chapters.

Personal Improvement Plans eventually build a case for a final Career Improvement Plan to be completed prior to graduation. These Personal Improvement Plans are a clear articulation of student goals, mentor's goals, and the degree's goals as they apply to each student's developing 
professional stature. IRE students are required to write a document which is organized with a cover page, table of contents, and an introduction summarizing the work of the semester as reflected in the individual improvement areas.

Each of the seven subject areas should be developed throughout the semester as the learning occurs. The content and format structure for each subject consist of the following labeled sections:

- Current Evaluation: describes current evaluation of self and addresses goals set in previous semesters in the chapter topic area.

- Progress this Semester: articulates the work that was done and the possible areas for improvement. States whether the previous Action Plan goal was met. If not, it becomes a new Improvement Goal with an Action Plan.

- Improvement Goals: describes in a numbered list, specific goals in the subject area. Use the SMART (Specific, Measurable, Achievable, Relevant, and Timely) strategy to articulate goals.

- Action Plan: includes active descriptions of specific actions to be taken to meet the Improvement Goals.

Table 1. ABET student outcome covered by PIP

\begin{tabular}{|c|c|c|c|}
\hline $\begin{array}{l}\text { ABET Student } \\
\text { Outcomes }\end{array}$ & Description & Supported by PIP & $\begin{array}{l}\text { Subjects written in PIP } \\
\text { (.) chapter number }\end{array}$ \\
\hline $\mathrm{d}$ & $\begin{array}{l}\text { an ability to function on } \\
\text { multidisciplinary teams }\end{array}$ & Chapter 1,3 & Leadership (1), Teamwork(3) \\
\hline $\mathrm{f}$ & $\begin{array}{l}\text { an understanding of professional and } \\
\text { ethical responsibility }\end{array}$ & Chapter 6,7 & $\begin{array}{l}\text { Professional Responsibility (6), } \\
\text { Ethical Decision Making (7) }\end{array}$ \\
\hline g & an ability to communicate effectively & Chapter 4,5 & $\begin{array}{l}\text { Technical Writing (4), } \\
\text { Presentation (5) }\end{array}$ \\
\hline i & $\begin{array}{l}\text { a recognition of the need for, and an } \\
\text { ability to engage in life-long learning }\end{array}$ & Chapter 2 & Learning about Learning (2) \\
\hline $\mathrm{h}$ & $\begin{array}{l}\text { the broad education necessary to } \\
\text { understand the impact of engineering } \\
\text { solutions in a global, economic, } \\
\text { environmental, and societal context }\end{array}$ & Chapter $1,2,6$ & \\
\hline $\mathrm{j}$ & a knowledge of contemporary issues & Chapter 6 & \\
\hline
\end{tabular}

\section{Students' perceptions}

As part of this study, students' perspectives on the PIP assignment were collected through two focus groups. Ten participants, who have completed the assignment more than once, were selected randomly among 30 students and then invited for focus group interviews. Eight out of ten students participated in the focus group. The participants consisted of two senior and six junior students, one female and seven male Caucasian students. The students were divided into two groups of four in two separate rooms to facilitate more discussion among participants. The participants were informed of the purpose of study and they consented on recording their discussion. The focus groups were conducted with several questions in mind. First, we wanted to know how well students understand the PIP process. Therefore, at the beginning of discussion 
we asked students to describe the PIP process. We also wanted to know if they are aware of the PIP's value. They are also asked which part of PIP they will use after graduation. The answers to this question clarify the value of PIP. And at the end, we asked them to discuss possible improvements can be made to the PIP process. The table 2 summarizes the results of the discussion.

One of our graduates, who is currently working as a mechanical engineer in a midsize company, recently sent an email to all IRE current students and faculty regarding the importance of PIP. The message includes the following:

\begin{abstract}
"It was not very long ago that I was writing personal and professional improvement plans at IRE. I can remember how I and many other students felt about these plans. Often times, we looked at them as busy work and not something we would really need to do once we had an engineering job. I want to end any thoughts you have like that.

Earlier this month, I received an email from my boss with two attachments. The first was a memo showing the dates and times of every employees end of the year review. The second attachment was a two page performance review that needed to be filled out and emailed to the president of the company prior to the meeting. I have attached the evaluation forms below."
\end{abstract}

The attached files were basically another version of PIP. This student was thrilled that he already gained skills to write a PIP and is ready to prove he is on the right track to achieve his professional goals.

\title{
Table 2. Results of focus group discussion
}

\begin{tabular}{|c|c|c|}
\hline $\begin{array}{l}\text { Questions discussed } \\
\text { during focus groups }\end{array}$ & Students' response & Our conclusion \\
\hline Describe PIP process & All eight participant describe the PIP process well & \\
\hline $\begin{array}{l}\text { Describe value of PIP } \\
\text { to your engineering } \\
\text { training }\end{array}$ & $\begin{array}{l}\text { They all value the PIP but they discussed the weaknesses of } \\
\text { the current version. Some of the ineffectiveness include: too } \\
\text { long, too structured, same as other metacognition memo, } \\
\text { have to rush fill in at the end of semester, self-awareness } \\
\text { should not be all about writing, I do it because it is required, } \\
\text { no mentorship to help, not obvious value. } \\
\text { They also discuss the benefits of PIP as learning writing, } \\
\text { know how to write one for promotion, }\end{array}$ & $\begin{array}{l}\text { The current version of } \\
\text { assignment is not as } \\
\text { effective as it should be. } \\
\text { They were not able to fully } \\
\text { describe the benefits and } \\
\text { value }\end{array}$ \\
\hline $\begin{array}{l}\text { What part of this } \\
\text { process will you use } \\
\text { after graduation? }\end{array}$ & $\begin{array}{l}\text { They mentioned that they will use the idea for continuous } \\
\text { improvement, but not with extensive writing if it is not } \\
\text { required. They believe that they will use some parts of this } \\
\text { process for promotion but maybe with different categories. } \\
\text { They said they will use small concise version of it. }\end{array}$ & $\begin{array}{l}\text { It can be concluded that all } \\
\text { the participants value the } \\
\text { PIP and that the PIP has } \\
\text { positive impact on them } \\
\text { since they will use the } \\
\text { process after graduation in } \\
\text { some forms }\end{array}$ \\
\hline
\end{tabular}




\section{Future improvement to the assignment}

Each semester, IRE is focused on continuous improvement to create a better program that produces high functioning engineers. The PIP was one document that has been looked at for this improvement. Faculty members have collected feedback on the PIP from IRE's academic advisory board and the present students. The feedback received falls into two key categories. The first is the structure and format of the PIP. Students are concerned that the document itself is over structured and at times, needlessly wordy. Students see the value in the PIP but worry too much effort is being spent on writing as opposed to reflection and improvement process.

The other category of feedback with regards to the PIP deals with the time frame in which it is done. Students often wait until the last weeks of the semester to perform the reflection process. As such, they do not spend the necessary time required to properly reflect on their semester and develop meaningful improvement in each of the PIP categories. Additionally, students do not have time to implement any changes before the end of the semester.

Over the coming semesters, IRE faculty members will review this feedback and look for ways to improve the PIP. Students and faculty are aware of the benefits of the PIP process and would like to find ways to iterate it to increase its value.

The ABET student outcomes reflect the value of a set of professional skills that are in addition to the well established technical and design skills associated with engineering graduates. The PIP process provides students the opportunity to create these professional skills as a part of their own engineering identity. The PIP uses a continuous improvement process similar to that used in engineering design, but now applied to the individual rather than to a product or process. With these attributes in mind, we believe the PIP is a best practice that could be adopted in any engineering education. Whether it is at the department level, course level, or for special cohorts such as honors programs, adaptation of the PIP can serve to benefit any engineering student in the pursuit of her or his degree.

\section{References}

1. Jackson, Norman. "Personal development planning: what does it mean?" Higher Education Academy from http://www. heacademy. ac. uk/ourwork/teachingandlearning (2001).

2. Clegg, Sue, and Sally Bradley. "Models of Personal Development Planning: practice and processes." British Educational Research Journal 32.1 (2006): 57-76.

3. Bullock, Kate, and Ian Jamieson. "The effectiveness of personal development planning." Curriculum journal 9.1 (1998): 63-77. 
4. Beausaert, Simon, et al. "Effect of using a personal development plan on learning and development." Journal of Workplace Learning 25.3 (2013): 145-158.

5. Zareena, Jainab, and Yasmeen Haider. "Role of Personal Development Planning (PDP) Program in Enhancing the Career Development of Engineering Students." International Journal (2013).

6. Allen, David. "Personal Development Planning” University of the West of England (2002). Available at http://www.economicsnetwork.ac.uk/handbook/pdp

7. Dearing, Ron. "Higher education in the learning society." (1997). Leeds, England: National Committee of Inquiry into Higher Education. Report of the National Committee, the National Committee of Inquiry into Higher Education. HMSO Norwich. Available at http://www.leeds.ac.uk/educol/ncihe/Last accessed 25/09/07.

8. Atlay, Mark. "Embedding PDP practice in the Curriculum," in Personal Development planning and Employability-The Higher Education Academy, (2006), Pg: 14. Available at :

http://www.heacademy.ac.uk/assets/documents/employability/pdp_and_employability_jan_2009.pdf

9. Habibi, Mohammad \& Alaei, Motahareh and Lillesve, Androw. "Integrating professionalism in a project-based engineering curriculum" Proceedings 2013 ASEE Annual Conference

10. Habibi, Mohammad and Ulseth, Ronald. "Time allocation Scaffolding in Project-Based Learning," Proceedings 2012 ASEE Annual Conference, AC 2012-4180

11. Ewart Dan et al. "Entrepreneurship in the Iron Range Engineering (IRE) Model," Proceedings 2011 ASEE Annual Conference, AC 2011-974 